\title{
Re-Constructing the Tutors-Tutees Relationships for Better Academic Performance in Universities Amidst Covid-19 New Normal
}

\author{
Bunmi Isaiah Omodan \\ School of Social Sciences and Language Education, \\ Bloemfontein Campus, \\ University of the Free State, \\ South Africa \\ Olugbenga A. Ige \\ School of Social Sciences and Language Education, \\ Bloemfontein Campus, \\ University of the Free State, \\ South Africa
}

DOI: https://doi.org/10.36941/mjss-2021-oo1o

Abstract

In the past, the success of Supplemental Instruction (Tutorial Sessions) depends on the tutors and tutees' physical and social relationships. However, the assumption exists that when there are no physical connections between the duos may affect their social interrelationships, impeding the success and intention of SI in the University classrooms. This study, therefore, investigates the current relationships amidst new normal towards SI and students performance. The study is underpinned by attachment theory to unravel the extent, importance and shortcomings of the assumed change in the relationship between the understudied. The study is guided by the Transformative Paradigm (TP) and Participatory Research (PR) to identify the possible dichotomies in their relationships. Purposive selection method was used to select five tutors and five tutees in a selected university in South Africa. Online (WhatsApp, email, and telephonic) interview was used to collect data from the participants. The data were subjected to thematic analysis. The result showed that that; struggles with the use and lack of Internet-of-Things and unstructured work-hours were the significant challenges that affected online tutorial sessions. On the other hand, the study also found out that students need ICT training and devices, including motivation for performance. Therefore, we recommend that training of ICT and provision of devices alongside strong motivation should be ensured.

Keywords: Tutors-tutees relationships, Supplemental Instruction, Attachment theory, COVID-19, Universities

\section{Introduction}

Supplemental Instruction (SI) is an academic support programme that originated from the University of Missouri, Kansas City, in the United States of America in 1973 by Dr Deanna Martin to revamp and rejig the depleting academic performance of students (Arendale, 2002; UKZN, 2015). This programme 
was adopted by the Department of Education in the United States of America as a productive programme and introduced in 155 higher institutions in 1995 (Arendale, 1997), which letter spread to other countries. Based on the success rate recorded by the universities in the operationalisation of the programme, over 1000 colleges and universities all over the world among which is the University of the Free State, South Africa, including other universities in the Republic of South Africa have adopted the programme with excellent results achieved thereafter (Adebola, 2019, Adebola, Tsotetsi \& Omodan, 2020). Studies also found out that students who participated in SI process significantly performed better than their counterpart who did not participate (Hurley \& Gilbert, 2008). On another note, it has also been found out that SI have contributed significantly to the reduction of drop-out rate in universities (Hurley \& Gilbert, 2008; Hodges, 2001). However, SI was designed to support students academically, especially in the historically difficult courses in either entry-level or the graduate-level (Arendale, 1997; Watty, 2020).

Adebola (2020) conceptualised SI as a mean to assist students who are disadvantaged and find it difficult to cope with their academics. Naidoo and Paideya (2015) also conceptualised it as an academic support system geared towards assisting students who have difficulty passing one or more specific courses. This programme is implemented through tutoring; that is, some specific tutors have gone through the stage of a particular course assigned to the students/tutees and assist them to pass. According to Philip, Jacques, Jane and Kym (2014), this programme also improves students' academic performance. This may be because it enables larger classes to be broken down into smaller units, handled by the tutors where tutors will have access to a limited number of students. This, according to Naidoo \& Paideya (2015) enable students to engage with themselves adequately. Therefore, SI could be described as an academic assistance programme geared towards increasing knowledge retention, academic performance and institutions' general productivity with collaborative and participatory learning strategies where students are allowed to think critically and construct knowledge of their own following principles of social constructivism. With this, individual students' critical thinking and skills develop to the extent that individual students can build his/her learning strategies with the help of instructors/facilitators.

The COVID-19 originated from Wuhan in China in late 2019 (Wuhan Municipal Health and Health Commission, 2020; Varalakshmi \& Arunachalam, 2020) and has significantly affected diverse nations of the world. Due to its contagious tendencies, this virus had led many countries to lock down in an attempt to prevent the virus from escalating (WHO, 2020), including South Africa. This, according to Omodan (2020a), and Dube (2020) affected all educational institutions, including the University system. The changes brought about by COVID-19 has led universities to introduce what is called 'work-from-home'. The staff and the students of the universities in different nations of the world were asked to work from home while the majority of academic activities were done online. As a result of this development, uncertainty on whether the supplemental Instruction could survive in the universities arose. This worry was because of the fact that the sustainability of SI in the university cannot be divorced from tutor-tutee physical relationships where tutees were arranged in smaller units and allocated to tutors for possible assistance in their problematic modules. Despite the robust purpose of SI in the university system, the advent of various lockdowns and work-from-home arrangements, universities have adopted the use of various strategies to continue with the implementation of the programme. In the selected university, Blackboard educational tool, WhatsApp, Zoom, among others, was adopted. The cause of disagreement here is whether various online platforms actually affect the expected social and professional relationships that are supposed to occur in tutoring sessions. This is contrary to Hughes \& Chen (2011) findings that positive relationships between students and their teachers enhance students' sense of belonging and promote their urge to be actively involved in the learning process.

Many challenges featured on the adoption of "new normal", the complete online teaching and learning that universities used as an alternative to physical contact sessions of the past. The study of Dube (2020) confirms that many students are affected because they have limited or no access to the internet to cope with the new teaching and learning system in schools. This may be connected to 
students with no access to the internet and the internet of things (Demirbilek, 2014). Apart from the availability or unavailability of resources, schools closure also resulted in students inability to catchup with the new ways of doing things (Adedoyin \& Soykan, 2020).

Among many other challenges is the lack of adequate facilities available to the students in order to attend to their academics works during COVID-19 lockdowns (Omodan, 2020a). This may constitute the conclusion of Bozkurt and Sharma (2020) that COVID-19 had exposed the education system to dangers. This argument confirms Ribeiro's (2020) opinion that the new digital transformation in instructional delivery is affected by the "logistical challenges and attitudinal modifications". Meanwhile, there is no doubt that the implementation of online learning depends on the availability of the Internet and the devices applicable to the Instruction. In the case of SI migration into the "new normal", challenges such as lack of internet of things and the needed devices may affect the implementation. Not only that, the tutees, most especially the ones in the first year of their academic pursuit may find it difficult to cope because the majority of the students in the selected university are from deep rural communities with little or no access to adequate internet of things (Omodan, 202ob). In order to ensure that both tutees and tutors work well amidst uncertainties, the place of attachment theory is imminent.

\section{Theoretical Framework}

This study adopted Attachment Theory because of its quest to understand the relationship between two entities. It is a theory that focuses on the relationships between people, either long or short term relationships (Cherry, 2018). Jone Bowlby propounded attachment theory in 1958 (Bowlby, 1969). According to Bowlby (1973), the theory believes that psychological connection exists among human beings, bringing out behaviours that establish close contact among them. Cherry (2018) maintains that this kind of psychological connection solidifies the closeness of children with an adult. That is, between school children and their teachers. This is also reflected in Krstic's (2015) argument that children gain self-reliance and learn better when adult provide predictable and consistent emotional support, mostly in a safe environment. Krstić (2015) further his argument by saying that when children have some sense of safety and feel comfortable, such environment encourages them to explore. According to Shaver \& Mikulincer (2011) and Riley (2012), Attachment Theory is the frontline theory in relationships studies. This is because it provides motivational behaviour that pilot people's interest towards one another (Riley, 2012).

From the above literature, we join our argument to support the opinion of Bergin and Bergin (2009 p. 142) that attachment relationships are branded by certain actions or inactions in children such as "showing a preference for or retreating to the attachment figure when threatened or upset, and using the attachment figure as a secure base while exploring their world". They proceeded by specifying the attachment action and inaction in adult as "attending to the child's needs, responding to the child's signals, and looking toward the child". In the case SI implementation during the physical contact session, tutees enjoy physical relationships with their tutors. They were able to engage themselves with questions and answer in smaller classroom settings where tutees can analyse tutors' facial expression and their physical demonstration. But the case is different in the present situation. This situation had practically hindered both the children/tutees' attachment behaviours and the adult/tutor. That is, the tutors could not physically attend to the need for tutees to their satisfaction. This situation is also contrary to Omodan and Tsotetsi (2018) view of student-teacher relationships as a positive motivation for students' academic performance. This is because the resultant effect of the attachment relationship is that students should enjoy academic support from the superiors (Davis, 2003), but the case during the COVID-19 lockdown is uncertain to whether the same relationships exist between the tutees and the tutors.

Therefore, this theory is relevant to underpin this study because it helps to predict and hypothesise the current relationships between the tutees and the tutors during the COVID-19 lockdown. This is to say that, there are likely tendencies for the tutees and tutors to experience 
unpleasant relationships which might have affected their productivity. Attachment Theory proposed that the close relationships between two or more people are significant to their productivity, which in this study is the student academic performance, but the current situation left this theory to remain a hypothesis. This becomes a hypothesis of whether or not the expected relationship exists between them, and whether the vacuuming affects the expected outcome of supplemental Instruction in universities. Further to guide the study is the below general question.

\section{Research Question}

From the above hypothesis, the following research question was raised to pilot the study;

- How can tutors-tutees relationships be re-constructed in the universities amidst Covid-19 new normal to aid students' and SI success?

\section{Research Objectives}

In order to fulfil the aims of the study, we have formulated two dominant research objectives to guide the process of answering the general question;

- The study examined the challenges faced/facing by the tutors and tutees in ensuring good relationships towards the success and/or the progress of Supplemental Instruction in universities during COVID-19 pandemic.

- The study also examined the solutions to alleviate/respond/correct the challenges.

\section{Methodology}

\subsection{Research Paradigm and Design}

This study was lensed by Transformative Paradigm (TP). TP was adopted because of its quest to understand social issues among the people and their confinement. Not only that, but it ontology also revolves around the understanding that political and social values construct the reality. That is, the relationship between the understudy could be understood with the focus on how to ameliorate the possible bridges in their togetherness. Based on this, Participatory Research (PR) was used as a research design for the study. This was adopted because it allows the people faced with the problem to join the process that provides a solution to the problem. According to Bergold and Thomas (2012), PR is a design that enables the researchers to plan the research alongside the understudy participant. In this case, it is believed that the research aims, the objectives, choice inquiry are developed and implement in collaboration with both the researched and the researcher. This is supported by Kleine, Pearson \& Holloway (2016), that PR value local knowledge, that is, it values the experience of the people facing the challenges under investigation to be part of the process to emancipate themselves. However, it researchers under this design are obliged to ensure the open-ended process to "leave space for surprises to emerge from the gap between the implicit or explicit framing of the research and the reality of the participants" (Kleine, Pearson \& Holloway, 2016). We implemented this principle by making sure that the concern subjects (tutors and Tutees) were selected to join the process of findings solution to the problem of the study and they were given the freedom to respond and make their contributions based on what they feel, faced/facing during the COVID-19 new normal.

\subsection{Participants and Method of Participants Selection}

The study participants consisted of five tutors and five tutees, making a total of 10 participants. The tutors were selected because they are foremost in the implementation of SI programme in universities. They are the one that takes care of the tutees by supporting them academically and 
ensure that they succeed in their studies. Tutors are also students who have passed the courses with excellent grade, assuming that they have the needed experience to assist the tutees to succeed. The tutees were also very important in the study because they are the one that receives the tutoring sessions with aims to enhance their own academic performance through tutoring or extra moral classes. Purposive selection method was used to select five tutors and 5 tutees in a selected university in South Africa. The use of purposive was found relevant because the targeted sample, tutors and tutees are the only entities that process the characteristics and the needed information and they were considered knowledgeable the phenomenon (Cresswell \& Plano-Clark, 2011). It also involves "information-rich cases yields insights and in-depth understanding rather than empirical generalisations" (Patton, 2002, p. 230). Our study believed that Tutors and Tutees are the best to give us in-depth, and rich information.

\section{Method of Data Collection}

The interview was adopted to elicit information from the participants. This was used because it enables us as researchers to inquire from the participants their feeling and experience regarding the issues. Questions around the objectives of the studies were posted to the participants, and they were given enough time and freedom to express their mind without any fear or intimidation from any angle. Questions around the objectives include; what are the challenges you faced/facing by as a tutor, and as a tutee in the other hand, in ensuring good relationships, vis-à-vis, towards the success and or the progress Supplemental Instruction during COVID-19 lockdown. Secondly, we also posted to them how they think we can jointly ensure solutions to ameliorate/respond/correct the challenges. Because of COVID-19 lockdown and the implementation of online learning in South African Universities, both staff and students are working from home. Therefore, we used WhatsApp, Emails, and telephone calls to conduct interviews with the participants. The only challenge we faced during the data collection process was that we could not read their emotions, as they were not physically present with us. However, the study did not need such feelings to understand and find solutions to the problem.

\section{Data Analysis and Ethical Consideration}

We adopted Thematic Analysis (TA) to make sense of the data. That we used TA analyse the data. TA was conceptualised as a way to categorise qualitative data into themes (Omodan, 2019). TA is also used to present data in themes about the focus of the study cum data with an illustration of details in divers' interpretations and meanings (Boyatzis, 1998). This is why it is relevant to this study because it enables us to analyse the data based on the objectives of the study. The data were guttered based on each objective, and the data under each objective were coded and categorised into different themes. Objectives number one have two themes, while objective number two have two themes as well. During the research process, ethical issues were observed as one of the process of conducting research to ensure that participants are protected against any harms (Dube, 2016). Based on this, we ensure that their identities and their responses were made confidential, and we ensure that their names were not included in anywhere in the study. During the analysis, we used pseudo names to represent their identities. The Tutors were described as follows: $\mathrm{TO}_{1}, \mathrm{TO}_{2}, \mathrm{TO}_{3}, \mathrm{TO}_{4}$, and $\mathrm{TO}_{5}$, while the TE1, TE2, TE3, TE4, and TE5.

\section{Data Presentation and Discussion of Findings}

In order to answer the research question; how can Tutors-tutees relationships be re-constructed in the Universities amidst Covid-19 New Normal? The data were collected and analysed in line with the objectives of the study. Under objective 1, we have two sub-themes, such as Struggles with the use of Internet-of-Things Tutorial Sessions and Unstructured Work-hours. Under objective 2, we have two 
sub-themes such as Introduction of ICT training and provision of Devices, and Motivation for Performance. See below table 1.

Table 1: Thematic representation of data based on the research objectives

\begin{tabular}{|c|c|}
\hline Objectives & Analysis of Sub-themes \\
\hline $\begin{array}{l}\text { 1. The study examined the challenges faced/facing by the } \\
\text { tutors and tutees in ensuring good relationships towards } \\
\text { the success and or the progress Supplemental Instruction } \\
\text { in universities during COVID-19 pandemic. }\end{array}$ & $\begin{array}{l}\text { 1. Struggles with the use and lack of Internet-of-Things } \\
\text { Tutorial Sessions. } \\
\text { 2. Unstructured Work-hours }\end{array}$ \\
\hline $\begin{array}{l}\text { 2. The study also examined the solutions to } \\
\text { alleviate/respond/correct the challenges. }\end{array}$ & $\begin{array}{l}\text { 1. Introduction of ICT training and provision of Devices } \\
\text { 2. Motivation for Performance }\end{array}$ \\
\hline
\end{tabular}

Objective 1 theme 1: Struggles with the use and lack of Internet-of-Things Tutorial Sessions

The use and not the use of internet of things, availability and utilisation of internet and devices have received great concern in the wake of COVID-19 new normal that has made educational institutions to resort to online teaching and learning (Kim, 2020). However, the trajectory has become a challenge for the students, and even the tutors to cope well with their duties. This also suffixes in the participant statements as shown below:

TO1: "The struggle was real when it comes to using blackboard, many of my Tutees were not familiar with blackboard, and they only came forward about that struggle only when they had to submit. As a tutor, I had to make sure that at the end of the day everyone managed to submit assignment successfully, so I had to help them even during the last minutes kindly".

TO2: "Some of the students were very ignorant they expected to be spoon-fed on everything. They come at last minute and demand assistance and also the issue of not taking the tutorial sessions serious". TE4: "some of us used to exit group discussion session without reason or because they were affected by the internet or device issues."

Deducing from the participants, TO1 reiterates that tutees are not familiar with the use of the blackboard learning system. This may be connected to the fact that the tutees are first-year students who have not got adequate knowledge about online learning before the lockdown. On the statement of $\mathrm{TO}_{2}$, it was also on the issue that tutees are ignorant of the use of the internet of things to enhance their studies and do not do their work as and when due. This action is assumed to post some stress to the tutors. The statement of $\mathrm{TE}_{4}$ is also on the same page by confirming that bad internets, lack of devices and knowledge to use devices affected their tutoring session because they become on and off during the sessions. Also, it was revealed that the lack of usage knowledge is not the only issue; the lack of access to the internet of things also contribute to the challenge. See the below statements:

TO4: "Some of them had no smartphones which will allow them to see/take part in our online sessions, as a result, I had to buy airtime to call them so that I can keep them up to date on what is happening, they also used to call me to check/keep up with the work we did."

TE1: "I was concerned about the lack of network connectivity and finding my colleagues regarding the group work because it is not easy to navigate the online things".

TE5: "The only challenges I faced was on the lack of computer, and many of my assignment could not be done via my android phones".

From the above participants' statements, one could say that many students, both tutees and tutors, have no enough devices and access to internet connectivity. $\mathrm{TO}_{4}$ opened up that many tutees use to call after when tutoring session has been concluded because they have no access to adequate devices to cope with their counterparts. On the statement of TE1, it was not easy for some of the tutees to respond well to their tutorial sessions because of lack of access to network connectivity and thereby affect their group works and other activities. $\mathrm{TE}_{5}$ also on the same page that he lacked a 
computer device and thereby affect him negatively during assignment activities. From these revelations coming from participants, it is clear that one of the challenges that tutors and tutees Struggle with the use and lack of Internet-of-Things Tutorial Sessions.

Based on the above analysis, it was revealed that the students struggled with using the internet of things as a result of the newness of the new normal. It was also confirmed that the students lack the needed devices to meet up with the challenges of online learning. This is undoubtedly a challenge to the relationship that co-exist between the tutees and tutors and outright negates the principles of attachments approach students' success. Therefore, when there is no good relationship, it affects students' self-reliance (Krstic, 2015; Krstić, 2015).

Objective 1 theme 2: Unstructured Work-hours

Another challenge that hinders the smooth relationships between the tutors and the tutees during the COVID-19 new normal is unstructured work hour and times among the tutees and tutees. To this end, they believed that since all their sessions take place online platforms, such as BlackBoard collaborate, WhatsApp, among others, they can attend at any time of their choices. This, in so many ways, has hindered their relationship for better performance. See below participants' statements:

TO1: "it become challenging as we were using WhatsApp as a platform of tutoring, I had to avail myself all day long. I had to be with my phone all day just to ensure that I am available whenever they needed help with something, I did not want them to think I was avoiding them, so as much as I had stuff to do, I had to make sure I respond to them as soon as I see their messages. This really helped in ensuring a positive relationship between my Tutees and me as they knew they could count on me".

TE1: "There is no clear time set by tutors to conduct our sessions; this give many of us a hard time to join the sessions".

TO2: "They would be online but never participate; they only show up when they are in need".

TO3: "The likes of learners who only participate when they are only in dire need of help and are not available when lessons are conducted."

TO4: "However, some students were always behind with their work due to the acclaimed network or system (BB) failure".

TO5: "Most tutees would ask for assistance on last minutes making it hard for them to understand everything in a short period of time".

TE3: Last but not least, some students did their work in the last minutes, asking questions that were already covered by the tutor in tutorial sessions.

From the statements of the participants showed that there is a trajectory of varied time schedules. This, according to $\mathrm{TO} 1$, is very challenging because there is no cleared time frame to when their sessions take place. She has to avail herself to the students at all time. In the same vein, TE1 also complain that there is no clear time set to carry out their tutorial activities. Though, her statement also indicated that the challenging situation leads to positive relationships between the duos. $\mathrm{TO}_{2}$ and $\mathrm{TO}_{3}$ also lament that many tutees do not participate in their tutorial sessions, but only come up whenever they need assistance from their tutors. This could be seen as a result of the feelings that they will get assisted at any time of their choice, not minding whether it is odd hours or not. This, according to the statement of $\mathrm{TO}_{4}$, it makes many of those tutors behind doing their works. $\mathrm{TO}_{5}$ and $\mathrm{TE}_{3}$ also confirmed that many tutees did not do their activities and or assignment as and when due, thereby resulting in last minutes solutions. The issues of workload and lack of enough time also came up. See the below statements:

TE2: "The problem I faced was that second semester I was under pressure since there was a lot of work and not enough time to prepare or understand the contents, but the tutor made it possible for me to understand because she would explain things thoroughly".

TE4: "In that case of too much work for us, the tutor was somehow offended most especially when we could not attend their WhatsApp sessions".

The statement of TE2 confirms that there is too much work which affected them to be proactive 
in the tutorial session. TE" even complained that the time available for them is not enough to meet up with their activities but in this case, the tutor that is responsible for this tutee was able to assist the tutee, but that does not take away the fact that time indifferences assist between them. The TE4 also supported this that too much workload hinders them from participating in the WhatsApp tutorial sessions, thereby making the tutor angry and displeased with them. From this analysis, one could see that irregular and unstructured working hours and time indifferences are a challenge affecting tutor-tutee relationships during COVID-19 new normal. The finding, therefore, confirmed that the is intermittent and unstructured time in the online tutorial sessions in the wake of COVID-19 and therefore could be seen a challenge.

Objective 2 theme 1: Introduction of ICT training and provision of Devices

In order to respond to the challenge number one, the place of more knowledge on the use of Information Communication Technology (ICT) is fundamental. This is important and increases knowledge and technology skills in learners, enhancing their performance (McPake et al. 2013; Manches and Plowman 2017). This also suffixes as one solution to smooth relationships between the tutee and tutors towards implementing SI in universities during COVID-19 new normal. See the below statements:
TO1: "If we are continuing with online tutoring, we are pleading with the A_STEP team to introduce online blackboard training for all first-year students to enable them to work well with us".
TE1: "All in all, using WhatsApp as a platform made our work easier throughout the year, and it makes our social relationships okay to some extent, therefore, there is need for some of us to learn more about online learning."
TO5: "tutees need to be provided with training and about the rules regulation so that they are aware of the pros and cons of the tutorial session and what consequences will they face if they don't comply."
TE4: "Well, since we are in the era of e-learning, proper applications such as Global Protect or consistent provision of data should be taken into consideration".

From the above statements, the needs for more knowledge about the use and the availability of devices suffixes. The statement of TO1 painstakingly requests from the SI department to organise training for the users most, especially the first-year students. It is assumed that first-year students do not have adequate knowledge of how to use and navigate the Blackboard teaching-learning system. This may be because the lockdown started immediately resumed in the university as first-year students. The participant TE1 commend that the use of WhatsApp helped them achieve but still link the achievement that more training is needed for the users to perform well. Participant $\mathrm{TO}_{5}$ also supported these claims that the tutees need to be exposed to more knowledge via training and to be able to have more knowledge about the rules and regulation of the tutorial sessions. The provision of the internet of things was also mentioned as one of the ways to ameliorate the above challenges. This was reiterated by $\mathrm{TE}_{4}$ that since the e-learning has become a new normal in the university system, there is a need to provide students with adequate application and data. This will make them respond well to the tutorial sessions and in turn, will solidify the relationships between the tutees and the tutors for the purpose of achieving the aims of SI.

Based on the above analysis, the study found out that the tutees need to be trained for a better understanding of the use of the internet of things. The study also found out that the training is not enough and must be accompanied by the provision of devices that will enhance the knowledge gained from the recommended training. This finding is consistent with the conclusion of Kim (2020) that students in the wake of COVID-19 needed to be provided with all necessary equipment that will avail them the opportunities and skills needed to survive the new system. To complement this, the argument of Steinmayr et al. (2019) also supports that students, in the wake of COVID-19, must be confident in the use of technology. By this, they will experience the feeling of success in the process of online teaching and learning.

Objective 2 theme 2: Motivation for Performance

Motivation, the driving force of students' academic performance (Sivrikaya, 2019) in any 
organisation is very fundamental to its progress, productivity and performance. This, according to the data gathered, was found as one of the suggestible solutions to the challenges. The participants believed that tutees need to be motivated for them to cope well and overcome the challenges inherent in the new normal. This suffixes in the statement of the participants. See the below statements:

TO4: "we need to always motivate tutees by providing them with pdf studying materials and offline videos for the lecture sections".

TE2: "We like when our lectures provide us with offline materials it really motivates me to study their modules at my own time."

TO2: "I would suggest that tutorial sessions should contribute a certain percentage of their final mark to motivate them to have a good relationship with us tutors as well as their peers and ensure that they participate in tutorials."

TO3: "I think what can be done for students to take the tutorial sessions serious is to award marks for attendance and students who causes trouble in the group".

The above statements justified that motivation is needed to ensure good relationships between the tutees and the tutors. As mentioned by $\mathrm{TO}_{4}$, the tutees need to be motivation by providing all their study materials, including videos of past sessions. TE2 also mentioned the issue of academic material as a point of motivation. In the same view, $\mathrm{TO}_{2}$ suggested that the tutorial session should contribute to the tutees' final marks; according to him, this will motivate them to participate. $\mathrm{TO}_{3}$ supported this that it will ginger the tutees to take their tutorial sessions very seriously. On the other hand, tutors are also encouraged to motivate tutees in their own little ways. This was mentioned in the below statements:

TE5: "Early responses from our tutors will make us happy, and lecturers would be appropriate and highly appreciated."

TO4: "They were corporative and did participate accordingly. What led to this is a simple and basic manner of how I related to them. I respected and valued them, they adjusted to that level of Ubuntu, and in return, we worked well together towards achieving the goal to progress as per the module is concerned."

$\mathrm{TE}_{5}$ lamented that prompt responses from their tutors and even lecturers make them happy and therefore, becomes a point of motivation. This was practicalised by $\mathrm{TO}_{4}$ and his tutees were cooperative and did actively involve in tutorial sessions because he was able to motivate them with good manner and respect, coupled with the spirit of Ubuntu. Ubuntu was conceptualised as love, respect, compassion, and togetherness (Tsotetsi \& Omodan, 2020). Hence, tutees' motivation becomes a way to ensure that good relations exist between the tutees and the tutors.

Based on the above analysis, it was found out that student needs the motivation to ensure productive relationships between the tutors and tutees in the wake of COVID-19 new normal. This finding is consistent with Sivrikaya (2019) result that both the intrinsic and extrinsic motivation in learners contribute significantly to the students' academic achievement. In the same vein, the finding of Akpur (2015) students' motivation is essential to academic output and therefore, significant to higher academic performance. To complement attachment theory, when student/tutor are motivated, there is a likelihood of good relationships between the tutors and tutors to achieve good performance in the system.

\section{Conclusion and Recommendations}

Based on the above findings, it is expedient to conclude that the major challenges confronting tutorstutees relationships are the inadequate knowledge of the internet of things and devices coupled with unstructured time arrangements between the duos. On the other hand, we also deemed it appropriate to conclude that the provision of adequate knowledge and training of Information 
Communication Technology (ICT) for the students and motivation is the dimension that could enhance tutor-tutees relationships to achieve the goal of Supplemental Instruction the time of COVID-19 new normal. Based on this, we recommend that the university through the Department of SI ensure that tutors and tutees are well trained with adequate internet-enabled devices. We also recommend that the tutors should ensure that the tutees are well motivated by accommodating their deficiencies and providing them with sufficient learning materials at their disposal.

\section{Reference}

Adebola, O. O. (2020). The Use of Supplemental Instruction in University Classrooms as a Strategy to Enhance the Academic Performance of First-year Students. Universal Journal of Educational Research, 8(11B), 6289-6296. https://doi.org/10.13189/ujer.2020.082268.

Adebola, O., Tsotetsi, C. T. \& Omodan, B. I. (2020). Enhancing students' academic performance in the university system: The perspective of supplemental Instruction. International Journal of Learning, Teaching and Educational Research. 19(5), 217-230. https://doi.org/10.26803/ijlter.19.2.x

Adedoyin, O. B. \& Soykan, E. (2020). COVID-19 pandemic and online learning: the challenges and opportunities, Interactive Learning Environments. https://doi.org/10.1080/10494820.2020.1813180

Arendale, D. (1997). Supplemental Instruction (SI): Review of Research Concerning the Effectiveness of SI from the University of Missouri-Kansas City and Other Institutions from across the United States.

Arendale, D. R. (2002). History of supplemental Instruction (SI): Mainstreaming of developmental education. Center for Research on Developmental Education and Urban Literacy, General College, University of Minnesota.

Bergin, C. \& Bergin, D. (2009). Attachment in the Classroom. Educational psychology Review, 21, 141-170.

Bergold, J. \& Thomas, S. (2012). Participatory Research Methods: A Methodological Approach in Motion. Forum Qualitative Sozialforschung / Forum: Qualitative Social Research, 13(1), 30. https://doi.org/10.2307/41756482

Bowlby, J. (1969). Attachment and Loss. Vol 1. Attachment. New York: Basick Books.

Bowlby, J. (1973). Attachment and loss: vol. 2. Separation, anxiety and anger. New York: Basic

Boyatzis, R. E. (1998). Transforming qualitative information: thematic analysis and code development. Sage Publications.

Bozkurt, A., \& Sharma, R. C. (2020). Emergency remote teaching in a time of global crisis due to Corona Virus pandemic. Asian Journal of Distance Education, 15(1), i-iv.

Braun, V. \& Clarke, V. 2006. Using thematic analysis in psychology. Qualitative research in psychology, 3(2), 77-101.

Cherry K. (2018). The Story of Bowlby, Ainsworth, and Attachment Theory; the Importance of Early Emotional Bonds. Updated February 19, 2018 https://www.verywellmind.com/what- is-attachment-theory2795337.

Cresswell, J. W. \& Plano-Clark, V. L. (2011). Designing and conducting mixed method research. 2nd Sage; Thousand Oaks, CA.

Davis, H. (2003). Conceptualising the role and influence of student-teacher relationships on children's social and cognitive development. Educational Psychologist, 38(4), 207-234.

Demirbilek, M. (2014). The 'digital natives' Debate: An Investigation of the digital Propensities of University students. Eurasia Journal of Mathematics, Science \& Technology Education, 10(2), https://doi.org/10.12973/eurasia.2014.1021a

Dube, B. (2020). Rural Online Learning in the Context of COVID-19 in South Africa: Evoking an Inclusive Education Approach. Multidisciplinary Journal of Educational Research, 10(2), 135-157. https://doi.org/10.4471/remie.2020.5607

Hughes, J. N. \& Chen, Q. (2011). Reciprocal effects of student-teacher and student- peer relatedness: Effects on academic self-efficacy. Journal of Applied Developmental Psychology, 32(5), 278-287.

Kim, J. (2020). Learning and Teaching Online During Covid-19: Experiences of Student Teachers in an Early Childhood Education Practicum. International Journal of Early Childhood, 52, 145-158. https://doi.org/10.1007/s13158-020-00272-6

Kleine, D., Pearson, G. \& Holloway, S. P. R. (2016). Participatory methods: Engaging children's voices and experiences in research. https://core.ac.uk/download/pdf/132212157.pdf

Krstić K. (2015). Attachment in the student-teacher relationship as a factor of school achievement. Teaching Innovations, 28 (3); 167-188.

Manches, A., \& Plowman, L. (2017). Computing education in children's early years: A call for debate. British Journal of Educational Technology, 48(1), 191-201. 
Naidoo, J. \& Vinodhani, P. (2015). Exploring the possibility of introducing supplemental Instruction at secondary school level mathematics education, school of education. South African Journal of Education. http://dx.doi.org/10.1570o/SAJE.V $35 \mathrm{~N}_{2}$ A1022

Omodan, B. I. (2019). A strategy to enhance crisis management between students and university authorities in Nigeria. PhD thesis, University of the Free State, South Africa.

Omodan, B. I. \& Tsotetsi, C. T. (2018). Student-Teacher Relationships as Panacea for Students' Academic Performance in Nigeria Secondary Schools: An Attachment Perspective. Journal of Social Studies Education Research, 9 (4), 82-101. https://files.eric.ed.gov/fulltext/EJ119910o.pdf

Omodan, B. I. (2020). Managing the Psycho-Social Vacuum of COVID-19 among Rural Learners through Ubuntu. Journal of Educational and Social Research, 10(6), 266-278. https://doi.org/10.36941/jesr-2020-0125

Omodan, B. I. (2020). The Vindication of Decoloniality and the Reality of COVID-19 as an Emergency of Unknown in Rural Universities. International Journal of Sociology of Education. 20, 1-26. http://doi.org/10.17583/rise.2020.5495

Patton, M. Q. (2002). Qualitative research and evaluation methods (3rd ed.). Thousand Oaks, CA: Sage.

Philip, D., Jacque, V., \& Jane, K. (2014). On the Effectiveness of Supplemental Instruction: A Systematic Review of Supplemental Instruction and Peer-Assisted Study Sessions Literature between 2001 and 2010. Review of Educational Research, 84(4). https://doi.org/10.3102/0034654314540007

Ribeiro, R. (2020, April 14). How university faculty embraced the remote learning shift. EdTech Magazine. https://edtechmagazine.com/higher/article/2020/04/how-university-faculty-embraced-remote-learningshift

Riley, P (2012). Attachment Perspectives On Classroom Relationships: Helping Ourselves Through Helping Others. Joint AARE APERA International Conference, Sydney 2012.

Shaver, P. R., \& Mikulincer, M. (2011). An attachment-theory framework for conceptualising interpersonal behavior. In L. M. Horowitz \& S. Strack (Eds.), Handbook of interpersonal psychology: Theory, research, assessment and therapeutic interventions (pp. 17-35). Hoboken, N.J.: Wiley.

Sivrikaya, A. H. (2019). The Relationship between Academic Motivation and Academic Achievement of the Students. Asian Journal of Education and Training. 5(2), 309-315. https://doi.org/10.20448/journal.522.2019.52.309.315

Tsotetsi, C. T. \& Omodan, B. I. (2020). Deconstructing power differentials in a supervision process: Mentoring in Ubuntu perspective. Ubuntu: Journal of Conflict Transformation, 9(1), 105-129. https://hdl.handle.net/10520/EJC-1eb5d4e406

Varalakshmi, R. \& Arunachalam, K. (2020). COVID 2019 - Role Of Faculty Members To Keep Mental Activeness Of Students. Asian Journal of Psychiatry, 51, 1-2. https://doi.org/10.1016/j.ajp.2020.102091

Watty, S. (2020). Supplemental Instruction. Diversity in Higher Education. https://doi.org/10.6084/m9.figshare.13309592.v1

WHO, 2020. Pneumonia of unknown cause - China. URL https://www.who.int/csr/don/o5- january-2020pneumonia-of-unkown-cause-china/en/ (accessed 3.31.20).

Wuhan Municipal Health and Health Commission (2020). Briefing on the Current Pneumonia Epidemic Situation in Our City. http://wjw.wuhan.gov.cn/front/web/showDetail/2019123108989 